\section{Limitations of Doppler ultrasound in the assessment of the function of prosthetic mitral valves}

\author{
John Chambers, Graham Jackson, David Jewitt
}

Cardiac Department, King's College Hospital, London J Chambers G Jackson

D Jewitt

Correspondence to Dr John Chambers, Department of Cardiology, Guy's Hospital, St Thomas Street, London SE1 9RT. Accepted for publication 16 November 1989 and ventricular function. Formulas for orifice area based on peak transmitral velocity and flow seem more likely to reflect the behaviour of normally functioning prostheses than those based on pressure half time.

There are numerous published reports of mean values for pressure half time and peak transmitral velocity (or derived gradient and orifice area) in normally functioning mitral prostheses $^{1-11}$ (table 1). The implicit assumption has been that dysfunction can be detected as a departure from these values, but this has not been established and important, unexplained inconsistencies remain.

Pressure half time is assumed to be a reliable indicator of orifice area but it rarely correlates inversely with annulus diameter and may be surprisingly similar in prostheses of widely different design. ${ }^{5610}$ Furthermore, the mean pressure half time for one valve type can be highly variable $e^{137}$ and is far longer for a tricuspid prosthesis than for a mitral prosthesis of the same diameter. ${ }^{1}$ Evidence is growing that factors other than the behaviour of the prosthesis may affect pressure half time; these include the shape and time course of left ventricular filling, stroke volume, and the transmitral pressure difference at the start of diastole. ${ }^{12-15}$ Except for \begin{abstract}
stroke volume for $15 \%$ of the varian annulus diameter when each of design of the prosthesis explained $18 \%$ of the variance in peak transmitral veloc eter did not contribute significa to define reliable normal ranges for prosthetic function independently of atrial
\end{abstract}

Table 1 Published values for pressure half time and effective orifice area (mean (SD) )

\begin{tabular}{|c|c|c|c|}
\hline Study & $\begin{array}{l}\text { Porcine } \\
\text { bioprosthesis }\end{array}$ & $\begin{array}{l}\text { Björk- } \\
\text { Shiley }\end{array}$ & $\begin{array}{l}\text { Starr- } \\
\text { Edwards }\end{array}$ \\
\hline \multicolumn{4}{|c|}{ Effective orifice area (Hatle formula): } \\
\hline Williams and Labowitz ${ }^{10}$ & $\begin{array}{c}2 \cdot 1(0 \cdot 7)^{\mathrm{H}, \mathrm{C}} \\
(\mathrm{n}=16)\end{array}$ & $\begin{array}{l}2.5(0.8) \\
(n=36)\end{array}$ & $\begin{array}{c}2.0(0 \cdot 3) \\
(n=10)\end{array}$ \\
\hline Panidis et al ${ }^{5}$ & $\begin{aligned} & 2 \cdot 2(0 \cdot 7)^{\mathrm{H}, \mathrm{C}} \\
&(\mathrm{n}=6)\end{aligned}$ & $\begin{array}{c}2 \cdot 2(0 \cdot 7) \\
(n=8)\end{array}$ & $\begin{array}{l}2 \cdot 1(0 \cdot 5) \\
(n=3)\end{array}$ \\
\hline Sagar et al ${ }^{9}$ & $\begin{array}{c}1.3-1 \cdot 9^{\mathrm{H}} \\
(\mathrm{n}=23)\end{array}$ & $\begin{array}{l}2 \cdot 1-2 \cdot 2 \\
(\mathrm{n}=17)\end{array}$ & \\
\hline Fawzy et al ${ }^{4}$ & $\begin{array}{l}1.5(0.3)^{\mathrm{C}} \\
(\mathrm{n}=14)\end{array}$ & & \\
\hline Alam et $a l^{8}$ & $\begin{aligned} & 2.0(0 \cdot 5)^{\mathrm{C}} \\
&(\mathrm{n}=105)\end{aligned}$ & & \\
\hline Cooper et al ${ }^{11}$ & $\begin{array}{l}2.6(0 \cdot 7)^{\mathrm{C}} \\
(\mathrm{n}=25)\end{array}$ & & \\
\hline \multicolumn{4}{|l|}{ Pressure half time: } \\
\hline Ryan et al ${ }^{3}$ & $\begin{array}{l}136(18)^{\mathrm{C}} \\
(\mathrm{n}=29)\end{array}$ & & \\
\hline Hatle and Angelsen? & $\begin{array}{l}135(25)^{\mathrm{C}} \\
(\mathrm{n}=13)\end{array}$ & & \\
\hline Gibbs et al ${ }^{12}$ & $\begin{array}{l}90(23)^{\mathrm{C}} \\
(\mathrm{n}=38)\end{array}$ & $\begin{array}{l}77(18) \\
(\mathbf{n}=31)\end{array}$ & $\begin{array}{l}127(24) \\
(n=5)\end{array}$ \\
\hline Present study & $\begin{array}{l}105(35)^{\mathrm{C}} \\
(\mathrm{n}=78)\end{array}$ & $\begin{array}{l}90(30) \\
(n=56)\end{array}$ & $\begin{array}{l}115(45) \\
(n=30)\end{array}$ \\
\hline
\end{tabular}

C, Carpentier-Edwards; H, Hancock. 
early work by Holen et al, ${ }^{16}$ no study of prosthetic function by Doppler ultrasound has reported flow information.

The aim of this study was to compare the contribution of valve type or annulus diameter and blood flow to pressure half time and peak transmitral velocity in three different types of mitral prosthesis-a porcine bioprosthesis (Carpentier-Edwards) and tilting disc (BjörkShiley) and caged ball (Starr-Edwards) mechanical prostheses.

\section{Patients and methods \\ PATIENTS}

A total of 182 consecutive patients with Carpentier-Edwards, Björk-Shiley, or StarrEdwards prostheses were referred either for routine assessment or because dysfunction was suspected. Fourteen prostheses were excluded: 10 because of appreciable aortic or mitral regurgitation on continuous wave Doppler and colour flow mapping (area of jet (by planimetry) more than $20 \%$ of receiving chamber area $)^{17}$ and four because cusp thickness exceeded $3 \mathrm{~mm} .^{18}$ No patient had reduced occluder motion. Four further patients were excluded because recordings were of poor quality. Abnormal left ventricular function was not a criterion for exclusion. Thirty five patients were in sinus rhythm, three were in paced rhythm, and the rest were in atrial fibrillation.

\section{DOPPLER STUDIES}

A phased array system was used (Hewlett Packard $77020 \mathrm{~A}$ ) with $1.9 \mathrm{MHz}$ continuous wave and $2.5 \mathrm{MHz}$ duplex probes. A full examination was performed in all views with sector imaging and colour flow Doppler to look for abnormalities of cusp or occluder motion and for significant aortic or mitral regurgitation. $M$ mode recordings were taken at standard levels. A continuous wave probe was then placed at the apex, aimed towards the mitral valve, and its position adjusted until optimal signal quality was obtained. Left ventricular inflow recordings were made on to thermal paper run at $100 \mathrm{~mm} / \mathrm{s}$.

\section{STATISTICAL ANALYSIS}

All diastolic measurements were made on the

Left ventricular inflow recorded by continuous wave Doppler. DTI, diastolic time interval; $T \frac{1}{2}$ pressure half time; $V$ max, peak left ventricular inflow velocity.

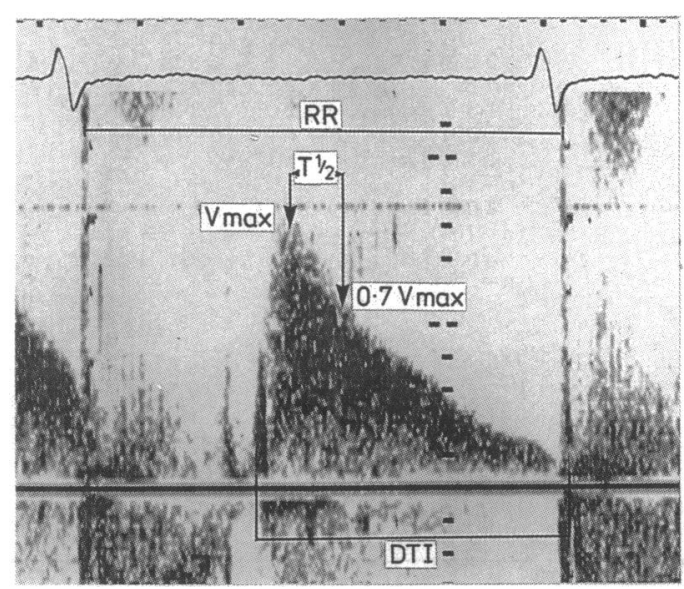

same three cycles in each patient. Most waveforms had a non-linear deceleration phase. Pressure half time ${ }^{19}$ was therefore calculated first by constructing a vertical line passing through the point of maximum velocity. A second line was then drawn parallel to the baseline at $0.7 \times$ peak velocity. Pressure half time was taken as the distance along the second line from the first vertical line to the outline of the waveform (figure). The diastolic time interval was measured from the start of the mitral opening artefact to the midpoint of the closing artefact. On long cardiac cycles where ventricular filling ended before the end of diastole, the filling period was taken to end where transmitral velocity had fallen to less than $0.2 \mathrm{~m} / \mathrm{s}$ for more than $200 \mathrm{~ms}$. The filling period was shorter than the diastolic time interval in $34(7 \%)$ of 492 cardiac cycles in a total of 19 patients. In all other instances the two periods were of identical length. The RR interval was measured from the end of the preceding diastolic period (figure). Mean values for pressure half time, peak transmitral velocity, diastolic time interval, filling period, and RR interval were calculated.

Stroke volume was calculated from $\mathrm{M}$ mode left ventricular recordings by the corrected cube formula described by Teicholz et al, ${ }^{20}$ which is not applicable in the presence of left ventricular dyskinesis. The formula could not, therefore, be applied in four cases. Cardiac output was calculated by the equation:

$$
\mathrm{CO}=(\mathrm{SV} \times \text { rate }) / 10^{3}
$$

when $\mathrm{CO}$ is cardiac output $(1 / \mathrm{min}), \mathrm{SV}$ is mean stroke volume $(\mathrm{ml})$, and rate is heart rate derived from the mean cycle length over three cycles. Transmitral flow was calculated on each cardiac cycle from the formula:

$$
\mathrm{Q}=10^{3} \times \mathrm{SVm} / \mathrm{DFP}
$$

when $Q$ is flow $(\mathrm{ml} / \mathrm{s}), \mathrm{SVm}$ is mean stroke volume (ml), and DFP is diastolic filling period (ms).

We used the SPSS ${ }^{\mathrm{x}}$ program on the University of London computer for statistical analysis. It was first performed using the three individual values for pressure half time and peak transmitral velocity, but this gave results similar to those with the mean values for each patient. This may have been because there was little beat to beat variation in $R R$ interval $(F=$ $0.97 ; p=0.38$ by one way analysis of variance). Mean values were therefore used for further analysis. The factors controlling pressure half time and peak transmitral velocity were then assessed by multiple regressions by entering variables from among the following: diastolic time interval, diastolic filling period, transmitral flow, valve type, annulus diameter, cardiac output, presence of aortic regurgitation. The results for diastolic time interval were skewed and required log transformation before being analysed. Dummy variables were constructed for prosthetic type and annulus diameter. A $p$ value of 0.01 was taken as significant for the multivariate analysis. 
Table 2 Results for all annulus diameters combined (mean (SD) )

\begin{tabular}{|c|c|c|c|c|c|}
\hline Variable & $\begin{array}{l}\text { Carpentier- } \\
\text { Edwards } \\
(n=78)\end{array}$ & $\begin{array}{l}\text { Björk- } \\
\text { Shiley } \\
(n=56)\end{array}$ & $\begin{array}{l}\text { Starr- } \\
\text { Edwards } \\
(n=30)\end{array}$ & $F$ value & $p$ value ${ }^{\star}$ \\
\hline $\begin{array}{l}\text { Ti (ms) } \\
\text { V max }(\mathrm{m} / \mathrm{s}) \\
\text { RR }(\mathrm{ms}) \\
\text { DTI }(\mathrm{ms}) \\
\text { Fill }(\mathrm{ms}) \\
\text { Age of valve (mnth) } \\
\text { Age at surgery (yr) }\end{array}$ & $\begin{array}{l}105(35) \\
1.5(0 \cdot 3) \\
760(150) \\
365(130) \\
365(130) \\
35(38) \\
59(13) \\
n=77\end{array}$ & $\begin{array}{c}90(30) \\
1.5(0 \cdot 4) \\
760(175) \\
395(140) \\
355(80) \\
51(43) \\
56(8) \\
n=53\end{array}$ & $\begin{array}{l}115(45) \\
1 \cdot 8(0 \cdot 3) \\
790(145) \\
440(120) \\
415(115) \\
107(90) \\
49(10) \\
n=30\end{array}$ & $\begin{array}{r}4 \cdot 0 \\
19 \cdot 1 \\
0.9 \\
2 \cdot 4 \\
5.5 \\
- \\
-\end{array}$ & $\begin{array}{l}<0.05 \\
<0.0001 \\
<0.01\end{array}$ \\
\hline $\begin{array}{l}\text { SV }(\mathrm{ml}) \\
\text { CO }(1 / \mathrm{min}) \\
\text { Flow }(\mathrm{ml} / \mathrm{s})\end{array}$ & $\begin{array}{c}60(25) \\
4 \cdot 8(1 \cdot 8) \\
170(60)\end{array}$ & $\begin{array}{c}55(20) \\
4 \cdot 6(1 \cdot 7) \\
165(55)\end{array}$ & $\begin{array}{c}68(20) \\
4.9(1.9) \\
165(80)\end{array}$ & $\begin{array}{l}2 \cdot 2 \\
2 \cdot 6 \\
2 \cdot 1\end{array}$ & \\
\hline
\end{tabular}

$\mathrm{T} \frac{1}{2}$, pressure half time; $R R, R R$ interval; $\mathrm{V}$ max, peak left ventricular inflow velocity; DTI, diastolic time interval; Fill, diastolic filling period; SV, stroke volume; $\mathrm{CO}$, cardiac output.

$\star$ By one way analysis of variance.

Table 3 Results for Carpentier-Edwards prostheses by diameter (mean (SD) )

\begin{tabular}{|c|c|c|c|c|c|c|}
\hline Variable & $\begin{array}{l}27 m m \\
(n=2)\end{array}$ & $\begin{array}{l}29 \mathrm{~mm} \\
(n=30)\end{array}$ & $\begin{array}{l}31 \mathrm{~mm} \\
(n=27)\end{array}$ & $\begin{array}{c}33 \mathrm{~mm} \\
(\mathrm{n}=19)\end{array}$ & $F$ values & p value * $^{*}$ \\
\hline $\begin{array}{l}T_{1} \frac{1}{2}(\mathrm{~ms}) \\
V_{\max }(\mathrm{m} / \mathrm{s}) \\
\mathrm{RR}(\mathrm{ms}) \\
\text { DTI }(\mathrm{ms}) \\
\text { Fill }(\mathrm{ms})\end{array}$ & $\begin{array}{l}90(10) \\
1 \cdot 7(0 \cdot 7) \\
645(135) \\
270(85) \\
270(85)\end{array}$ & $\begin{array}{l}115(35) \\
1.5(0.3) \\
830(155) \\
435(130) \\
405(105)\end{array}$ & $\begin{array}{l}105(40) \\
1.5(0.3) \\
755(150) \\
365(115) \\
355(100)\end{array}$ & $\begin{array}{c}95(30) \\
1.4(0 \cdot 2) \\
680(100) \\
335(70) \\
330(70)\end{array}$ & $\begin{array}{l}1 \cdot 2 \\
0 \cdot 8 \\
4 \cdot 9 \\
4 \cdot 1 \\
4 \cdot 2\end{array}$ & $\begin{array}{l}<0.001 \\
<0.001 \\
<0.001\end{array}$ \\
\hline $\begin{array}{l}\text { SV }(\mathrm{ml}) \\
\text { CO }(1 / \mathrm{min}) \\
\text { Flow }(\mathrm{ml} / \mathrm{s})\end{array}$ & $\begin{array}{l}n=2 \\
45(15) \\
4 \cdot 3(2 \cdot 3) \\
180(110)\end{array}$ & $\begin{array}{c}n=30 \\
60(20) \\
4 \cdot 3(1 \cdot 6) \\
145(50)\end{array}$ & $\begin{array}{c}n=27 \\
60(30) \\
4 \cdot 9(2 \cdot 1) \\
180(70)\end{array}$ & $\begin{array}{c}n=18 \\
60(20) \\
5 \cdot 4(1 \cdot 5) \\
185(45)\end{array}$ & $\begin{array}{l}0 \cdot 2 \\
2 \cdot 2 \\
2 \cdot 9\end{array}$ & $<0.05$ \\
\hline
\end{tabular}

See footnote to table 2 for abbreviations.

$\star$ By one way analysis of variance.

\section{Results}

MEAN PRESSURE HALF TIME AND PEAK

TRANSMITRAL VELOCITY

These are shown for each valve type (table 2) and by annulus diameter within each valve type (tables 3-5). Pressure half time was shorter in the Björk-Shiley prosthesis than in either of the other valve types $(p<0.05)$ and peak transmitral velocity was highest in the StarrEdwards prostheses $(p<0.0001)$. The relative contribution of prosthesis related and other factors was, however, unclear from this preliminary analysis because there were coexistent differences in cardiac output and filling period between different valve types and annulus diameters. Further multivariate analysis was therefore performed to try to dissociate these factors.

MULTIVARIATE ANALYSIS OF PRESSURE HALF TIME Filling time and stroke volume were the variables that best explained the variance in mean pressure half time (table 6). Valve design also contributed, but annulus diameter, transmitral flow, or the presence of mild aortic regurgita- tion did not. All the contributory variables together explained $32 \%$ of the variance in pressure half time.

Even when each valve type was considered separately, annulus diameter did not explain a significant proportion of the variance in pressure half time (Carpentier-Edwards $4.9 \%, \mathrm{~F}_{3,72}$ $=1 \cdot 2$; Björk-Shiley $4.5 \%, F_{3,51}=0.8$; StarrEdwards $\left.7 \cdot 7 \%, F_{2,25}=1 \cdot 1\right)$. The effect of filling time was greater in the Björk-Shiley prostheses $\left(24 \%, F_{1,53}=16.7 ; p=0.0001\right)$ than in the Starr-Edwards $\left(20 \%, F_{1,26}=6.7\right.$; $\mathrm{p}=0.016$ ), or Carpentier-Edwards prostheses $\left(13 \%, F_{1,74}=10.6 ; p=0.0017\right)$.

To exclude the possibility that filling period was controlled by valve type or annulus diameter and that pressure half time could therefore be related indirectly to prosthetic factors, further analysis of filling period was performed. The filling period was strongly related to the $R R$ interval $\left(68 \%, F_{1,162}=343\right.$; $\mathrm{p}<0.00001)$ in all three prosthetic designs and multivariate analysis showed little contribution from valve design alone $\left(5.0 \%, \mathrm{~F}_{2,161}=4.2\right.$; $\mathrm{p}=0.016)$ or annulus diameter alone $(4.0 \%$, $\mathrm{F}_{3,160}=2 \cdot 2 ; \mathrm{p}=0.09$ ).

Table 4 Results for Björk-Shiley prostheses by diameter (mean (SD))

\begin{tabular}{|c|c|c|c|c|c|c|}
\hline Variable & $\begin{array}{l}25 \mathrm{~mm} \\
(\mathrm{n}=1)\end{array}$ & $\begin{array}{l}27 m m \\
(n=18)\end{array}$ & $\begin{array}{l}29 \mathrm{~mm} \\
(n=19)\end{array}$ & $\begin{array}{l}31 \mathrm{~mm} \\
(n=13)\end{array}$ & $\begin{array}{l}33 \mathrm{~mm} \\
(n=5)\end{array}$ & $F$ values \\
\hline $\begin{array}{l}\mathrm{T} \frac{1}{2}(\mathrm{~ms}) \\
\mathrm{V} \max (\mathrm{m} / \mathrm{s}) \\
\text { RR }(\mathrm{ms}) \\
\text { DTI (ms) } \\
\text { Fill (ms) }\end{array}$ & $\begin{array}{c}100 \\
1 \cdot 9 \\
1065 \\
615 \\
485\end{array}$ & $\begin{array}{l}100(35) \\
1 \cdot 6(0 \cdot 3) \\
755(180) \\
405(130) \\
360(70)\end{array}$ & $\begin{array}{l}90(25) \\
1.4(0.4) \\
760(185) \\
395(155) \\
350(85)\end{array}$ & $\begin{array}{c}90(25) \\
1 \cdot 6(0 \cdot 3) \\
760(170) \\
390(130) \\
360(80)\end{array}$ & $\begin{array}{l}75(25) \\
1.3(0.6) \\
710(165) \\
340(105) \\
315(70)\end{array}$ & $\begin{array}{l}0.7 \\
1.4 \\
0 \cdot 8 \\
0.9 \\
1 \cdot 1\end{array}$ \\
\hline $\begin{array}{l}\text { SV }(\mathrm{ml}) \\
\text { CO }(1 / \mathrm{min}) \\
\text { Flow }(\mathrm{ml} / \mathrm{s})\end{array}$ & $\begin{array}{c}n=1 \\
60 \\
3 \cdot 4 \\
125\end{array}$ & $\begin{array}{l}n=18 \\
50(20) \\
4 \cdot 2(1 \cdot 9) \\
145(60)\end{array}$ & $\begin{array}{l}n=16 \\
60(25) \\
5 \cdot 0(1 \cdot 6) \\
175(45)\end{array}$ & $\begin{array}{c}n=13 \\
65(20) \\
5 \cdot 0(1 \cdot 5) \\
180(50)\end{array}$ & $\begin{array}{l}n=5 \\
45(10) \\
4 \cdot 0(1 \cdot 5) \\
150(55)\end{array}$ & $\begin{array}{l}1.4 \\
0.7 \\
1.2\end{array}$ \\
\hline
\end{tabular}


Table 5 Results for Starr-Edwards prostheses by diameter (mean (SD))

\begin{tabular}{|c|c|c|c|c|c|}
\hline Variable & $\begin{array}{l}28 m m \\
(n=7)\end{array}$ & $\begin{array}{l}30 \mathrm{~mm} \\
(\mathrm{n}=14)\end{array}$ & $\begin{array}{l}32 \mathrm{~mm} \\
(\mathrm{n}=9)\end{array}$ & $F$ values & pvalue \\
\hline $\begin{array}{l}\mathrm{T} \frac{1}{2}(\mathrm{~ms}) \\
\mathrm{V} \max (\mathrm{m} / \mathrm{s}) \\
\mathrm{RR}(\mathrm{ms}) \\
\mathrm{DTI}(\mathrm{ms}) \\
\text { Fill }(\mathrm{ms})\end{array}$ & $\begin{array}{l}130(25) \\
1 \cdot 8(0 \cdot 2) \\
840(85) \\
460(75) \\
440(50)\end{array}$ & $\begin{array}{l}100(40) \\
1 \cdot 8(0 \cdot 2) \\
740(170) \\
445(125) \\
415(135)\end{array}$ & $\begin{array}{l}125(60) \\
1.9(0 \cdot 4) \\
775(190) \\
415(150) \\
395(130)\end{array}$ & $\begin{array}{l}1 \cdot 1 \\
0.3 \\
0.5 \\
0.3 \\
0.3\end{array}$ & \\
\hline $\begin{array}{l}\text { SV }(\mathrm{ml}) \\
\text { CO }(1 / \mathrm{min}) \\
\text { Flow }(\mathrm{ml} / \mathrm{s})\end{array}$ & $\begin{array}{l}n=7 \\
70(10) \\
5 \cdot 2(0 \cdot 9) \\
165(35)\end{array}$ & $\begin{array}{c}n=14 \\
50(15) \\
4 \cdot 1(1 \cdot 7) \\
135(65)\end{array}$ & $\begin{array}{c}n=9 \\
70(20) \\
5 \cdot 9(2 \cdot 4) \\
210(105)\end{array}$ & $\begin{array}{l}6 \cdot 9 \\
5 \cdot 4 \\
2 \cdot 4\end{array}$ & $\begin{array}{l}<0.01 \\
<0.02\end{array}$ \\
\hline
\end{tabular}

See footnote to table 2 for abbreviations.

$\star$ By one way analysis of variance.

Table 6 Results of multivariate regression analyses of the variance in pressure half time

\begin{tabular}{|c|c|c|c|c|}
\hline Variable & $\begin{array}{l}\text { Variance } \\
\text { explained }\end{array}$ & $F$ value & p value & $\begin{array}{l}\text { Standard } \\
\text { error }\end{array}$ \\
\hline $\begin{array}{l}\text { Diastolic filling time } \\
\text { Stroke volume } \\
\text { Diastolic time interval } \\
\text { Prosthetic design } \\
\text { Mean transmitral flow } \\
\text { Coexistent aortic prosthesis } \\
\text { Annulus diameter } \\
\text { Presence of aortic regurgitation }\end{array}$ & $\begin{array}{l}19^{\circ} \circ \\
15^{\circ} \circ \\
11^{\circ} \circ \\
5 \cdot 6^{\circ} \circ \\
2 \cdot 0^{\circ} \circ \\
0 \cdot 7^{\circ} \\
0 \cdot 4^{\circ} \\
0 \cdot 0^{\circ}\end{array}$ & $\begin{array}{c}37 \\
26 \\
19 \\
4 \cdot 6 \\
2 \cdot 0 \\
1 \cdot 3 \\
0 \cdot 2 \\
0 \cdot 0\end{array}$ & $\begin{array}{l}<0.00001 \\
<0.00001 \\
<0.00001 \\
<0.02 \\
0 \cdot 12 \\
0.25 \\
0.95 \\
0.85\end{array}$ & $\begin{array}{l}33 \\
35 \\
35 \\
36 \\
38 \\
37 \\
37 \\
37\end{array}$ \\
\hline
\end{tabular}

MULTIVARIATE ANALYSIS OF PEAK TRANSMITRAL VELOCITY

Prosthetic design, cardiac output, and annulus diameter together explained $22 \%$ of the variance in peak transmitral velocity, of which most was explained by design alone (18\%, $\left.\left(\mathrm{F}_{2,161}=17 \cdot 2 ; \mathrm{p}<0.00001\right)\right)$. Cardiac output explained only $2 \cdot 7 \%,\left(F_{1,158}=4.3\right)$ and annulus diameter alone was not a determinant of peak transmitral velocity even within each prosthetic design (Carpentier-Edwards 3.5\%, $\mathrm{F}_{3,74}=0.8 ;$ Björk-Shiley $6.0 \%, \mathrm{~F}_{3,52}=1 \cdot 1$; Starr-Edwards $2.0 \%, F_{2,27}=0.3$ ). The prosthetic designs differed in their response to flow. Peak transmitral velocity was weakly but significantly correlated with cardiac output $(r=0.443 ;$ SE $0.24 ; p<0.02)$.

\section{Discussion}

In the normally functioning mitral prostheses in this study, the variability in pressure half time was better explained by the diastolic filling period and stroke volume than by the design of the prosthesis. Annulus diameter did not contribute significantly.

\section{DETERMINANTS OF PRESSURE HALF TIME}

Theoretical work suggests that pressure half time is related not only to mitral orifice area, but also to the transmitral pressure difference at the start of diastole, to stroke volume, and to left atrial and ventricular compliance. ${ }^{14} 15$ In a flow simulator we showed that the pressure half time in mitral bioprostheses reflects the shape and time course of the left ventricular filling curve $^{12}$ and this can be regarded as a model for the effect of left atrial and ventricular compliance. Altered atrial compliance may also explain the deterioration soon after balloon dilatation in the correlation between pressure half time and the orifice area measured by planimetry in patients with native mitral stenosis. $^{21}$

The present study gives clinical evidence for a relation between pressure half time and both stroke volume and heart rate. All variables together, however, explained only $32 \%$ of the variance in pressure half time. Differences in ventricular compliance probably accounted for part of the residual variability, although inaccuracies in measurement or individual patient variability may also have contributed.

\section{EFFECT OF HEART RATE ON PRESSURE HALF TIME}

Morrow et al showed that in native mitral valves the proportion of left atrial pressure lost in the first $100 \mathrm{~ms}$ of diastole was high in pure mitral regurgitation, low in pure mitral stenosis, and intermediate in normal valves or in valves with combined stenosis and regurgitation. ${ }^{22}$ This observation led to the concept of pressure half time, which was the time taken for the peak transmitral pressure gradient at cardiac catheterisation to fall to one half. ${ }^{2324}$ This was thought to be relatively independent of flow, but the original data show a large scatter in results with pressure half times of from 110 to $170 \mathrm{~ms}$ over a range of instantaneous heart rates from 63 to 86 beats/minute in atrial fibrillation. ${ }^{24}$ Retrospective analysis of these data showed a statistically significant inverse relation between pressure half time and heart rate. ${ }^{14}$

An inverse relation between pressure half time and heart rate was also found during pacing in patients with permanent pacemaker systems and mitral prostheses. ${ }^{13}$ Heart rate probably affects pressure half time in several ways. Orifice area may sometimes increase at higher heart rates, although at the cardiac outputs seen in the present study most valves would be expected to have been fully open. ${ }^{25}$ Furthermore, pressure half time also falls as rate increases in patients with St Jude bi-leaflet tilting disc prostheses, which are expected to be fully open at low flows. ${ }^{26}$ Changes in heart rate may also affect left ventricular compliance, stroke volume, and left atrial pressure. ${ }^{27-29}$ The effect of these factors may differ in individuals 
because in the present study the observed relation between heart rate and pressure half time varied widely. Therefore no simple correction of pressure half time for rate can be possible.

\section{EFFECT OF ANNULUS DIAMETER AND TYPE OF PROSTHESIS}

The inability of this study to show a major effect of prosthetic design and annulus diameter on pressure half time need not necessarily rule out an effect of orifice area. In the Carpentier-Edwards porcine bioprosthesis actual orifice area may vary by about $20 \%$ in valves of the same annulus diameter ${ }^{30}$ and in the Starr-Edwards valve there is no simple central orifice. The Björk-Shiley tilting disc prosthesis, however, has an area available for flow that is expected to reflect the annulus diameter more closely, but even in this valve type pressure half time was not related statistically to annulus diameter. It is possible that the type of prosthesis might have contributed more to the variance in pressure half time had valves with larger orifice areas such as the St Jude prosthesis been studied. ${ }^{31}$ If, however, valve behaviour were a major determinant of pressure half time, this should have been found in the prostheses studied because these show wide differences during in vitro testing. ${ }^{32}{ }^{33}$ Furthermore, we found that pressure half time is only moderately related to orifice area in vitro. ${ }^{12}$ Thus there is good evidence that in normally functioning mitral prostheses pressure half time does not reliably reflect orifice area.

\section{PEAK TRANSMITRAL VELOCITY}

Peak transmitral velocity was most closely related to prosthetic design although in the Starr-Edwards prostheses it was also affected by cardiac output. This result is consistent with hydrodynamic work, showing that of the three valve types studied the Starr-Edwards offers the greatest resistance to flow and therefore produces the steepest slope when transmitral velocity is plotted against flow. ${ }^{32} 33$ A close relation between flow and peak velocity has also been shown in fixed diaphragm obstructions. ${ }^{34}$

\section{CLINICAL IMPORTANCE}

The relatively minor effect of prosthetic design on pressure half time has important practical implications. Numerous studies have attempted to define normal ranges for prosthetic function based on pressure half time or effective orifice area derived from the Hatle formula (220/pressure half time) (table 1). Differences between studies are likely to be related more to atrial or ventricular factors than to prosthetic function. Thus the range in mean pressure half time reported as normal for CarpentierEdwards prostheses, $90-136 \mathrm{~ms}$, is wider than for the three prosthetic designs in this study.

It is therefore very unlikely that pressure half time can reliably detect minor changes in prosthetic function. Studies claiming that Doppler is highly sensitive for the detection of prosthetic obstruction have used patients already defined as normal or dysfunctional on clinical grounds. ${ }^{3489}$ None the less, severe prosthetic obstruction is associated with a lengthened pressure half time. ${ }^{3}$ Furthermore, aortic regurgitation has been reported to lengthen pressure half time when the mitral valve is normal, but to have no effect where there is severe mitral stenosis. ${ }^{35} 36$ These observations are consistent with the suggestion that orifice area is the most important constraint on pressure half time where there is significant mitral stenosis, whereas where the orifice is relatively large, other factors will be more important. The point at which this transition occurs is not yet known.

This study showed that pressure half time was statistically more closely related to diastolic filling time and stroke volume than to prosthetic design or annulus diameter. Peak transmitral velocity was related to prosthetic design and in the Starr-Edwards valve also to cardiac output. Pressure half time is unlikely to detect small changes in orifice area. Orifice area formulas based on transmitral velocity and flow such as the Gorlin formula ${ }^{25}$ are likely to reflect prosthetic mitral behaviour more accurately than the Hatle formula, which should be applied with caution in normally functioning mitral valve prostheses.

J C was supported by a British Heart Foundation Junior Fellowship. We thank Mr D Lowe for statistical advice and D D A Shears for the computer analysis.

1 Gibbs JL, Wharton GA, Williams GJ. Doppler echocardiographic characteristics of the Carpentier-Edwards cardiographic characteristics of the Cart.

2 Gibbs JL, Wharton GA, Williams GJ. Doppler ultrasound of normally functioning mechanical mitral and aortic valve prostheses. Int J Cardiol 1988;18:391-8.

3 Ryan T, Armstrong WF, Dillon JC, Feigenbaum H. Doppler echocardiographic evaluation of patients with porcine mitral valves. Am Heart J 1986;111:237-44.

4 Fawzy ME, Halim M, Ziady G, Mercer E, Phillips R, Andaya W. Haemodynamic evaluation of porcine bioprostheses in the mitral position by Doppler echocardiography. Am J Cardiol 1987;59:643-6.

5 Panidis IP, Ross J, Mintz GS. Normal and abnormal prosthetic valve function as assessed by Doppler echocardiography. J Am Coll Cardiol 1986;8:317-26.

6 Simpson IA, Reece IJ, Houston AB, Hutton I, Wheatley DJ, Cobbe SM. Non-invasive assessment by Doppler ultrasound of 155 patients with bioprosthetic valves: a
ulicher ultrasound of 155 patients with bioprosthetic valves: a
comparison of the Wessex porcine, low profile IonescuShiley, and Hancock pericardial bioprostheses. Br Heart J 1986;56:83-8.

7 Hatle L, Angelsen B. Doppler ultrasound in cardiology. Philadelphia: Lea and Febiger, 1985:196.

8 Alam M, Rosman HS, Lakier JB, et al. Doppler and echocardiographic features of normal and dysfunctioning bioprosthetic valves. J Am Coll Cardiol 1987;10:851-8.

9 Sagar KB, Wann S, Paulsen WHJ, Romhilt DW. Doppler echocardiographic evaluation of Hancock and BjörkShiley prosthetic valves. J Am Coll Cardiol 1986;7:681-7.

10 Williams GA, Labovitz AJ. Doppler hemodynamic evaluation of prosthetic (Starr-Edwards and Bjork-Shiley) and bioprosthetic (Hancock and Carpentier-Edwards) cardiac valves. Am J Cardiol 1985;56:325-32.

11 Cooper DM, Stewart WJ, Schiavone WA, et al. Evaluation of normal prosthetic valve function by Doppler echocardiography. Am Heart J 1987;114:576-82.

12 Chambers JB, Cochrane T, Black MM, Jackson G. In vitro validation of the assessment by Doppler ultrasound of valital mitral bioprosthetic function Cardiovasc $R$ of 1989;23:1007-14.

13 Chambers J, McLoughlin N, Rapson A, Jackson G. Effect of changes in heart rate on pressure half time in normally functioning mitro:

14 Thomas JD, Weyman AE. Doppler mitral pressure half time: a clinical tool in search of theoretical justification. $J$

15 Loyd D, Ask P, Wranne B. Pressure half time does not always predict mitral valve area correctly. J Am Soc Echo 1988;1:313-21.

16 Holen J, Hoie J, Saub B. Obstructive characteristics of Björk-Shiley, Hancock, and Lillehei-Kaster prosthetic mitral valves in the immediate postoperative period. Acta Med Scand 1978:204:5-10. 
17 Helmcke F, Nanda NC, Hsuing MC, et al. Color Doppler assessment of mitral regurgitation with orthogonal planes. Circulation 1987;75:175-83.

18 Alam M, Lakier JB, Pickard SD, Goldstein S. Echocardiographic evaluation of porcine bioprosthetic valves: diographic evaluation of porcine bioprosthetic valves: Am J Cardiol 1983;52:309-15.

19 Hatle L, Angelsen B, Tromsdal A. Noninvasive assessment of atrioventricular pressure half time by Doppler ultrasound. Circulation 1979;60:1096-104.

20 Teicholz LE, Kreulen T, Herman MV, Gorlin R. Problem in echocardiographic volume determination: echocardiographic-angiographic correlation in the presence or absence of asynergy. Am J Cardiol 1976;37:7-11.

21 Kennedy JW, Trenholme SE, Kasser IS. Left ventricular volume and mass from single plane cineangiocardiograms. $A$ comparison of anteroposterior and right anterior oblique methods. Am Heart J 1970;80:343-52.

22 Morrow AG, Braunwald E, Haller JA, Sharp EH. Left atrial pressure pulse in mitral valve disease. A correlation of pressure obtained by transbronchial puncture with the valve lesion. Circulation 1957;16:399-405.

23 Libanoff AJ, Rodbard S. Evaluation of the severity of mitral stenosis and regurgitation. Circulation 1966;33:218-26.

24 Libanoff AJ, Rodbard S. Atrioventricular pressure half time: measure of mitral valve orifice area. Circulation 1968;38:144-50.

25 Chambers JB, Cochrane T, Black MM, Jackson G. The Gorlin formula in mitral bioprostheses validated against directly observed orifice area. J Am Coll Cardio 1989;13:348-53.

26 Rosamond TL, Vered Z, Spray T, Perez JE. The pressure half time overestimates valve area with exercise: validation in St Jude prosthetic valves [Abstract]. Circulation 1988;78(suppl II):608.
27 Noble MIM, Milne ENG, Goerke RJ, et al. Left ventricular filling and diastolic pressure-volume relations in the conscious dog. Circ Res 1969;24:269-83.

28 Grossman W, McLaurin LP. Diastolic properties of the left vensman W, McLaurin LP. Diastolic prope

29 Ross J, Linhart JW, Braunwald E. Effects of changing heart rate in man by electrical stimulation of the right atrium. Circulation 1965;32:549-58.

30 Walker DK, Scotten LN, Modi VJ, Brownleee RT. In vitro assessment of mitral valve prosthesis. J Thorac Cardiovasc Surg 1980;79:680-8.

31 Weinstein IR, Marbarger JP, Perez JE. Ultrasonic assessment of the St Jude prosthetic valve: $M$ mode, twodimensional, and Doppler echocardiography. Circulation 1983;68:897-905.

32 Gabbay S, McQueen DM, Yellin EL, Becker RM, Frater $R W M$. In vitro hydrodynamic comparison of mitral valve prosthesis at high flow rates. J Thorac Cardiovasc Surg 1978;76:771-87.

33 Gabbay S, McQueen DM, Yellin EL, Frater RWM In vitro hydrodynamic comparison of mitral valve bioprosthesis. hydrodynamic comparison of mitra
Circulation 1979;60(suppl 1):62-70.

34 Requarth JA, Goldberg SJ, Vasko SD, Allen HD. In vitro verification of Doppler prediction of transvalve pressure
gradient and orifice area in stenosis. Am J Cardiol gradient and orific

35 Grayburn PA, Smith MD, Gurley JC, et al. Effect of aortic regurgitation on the assessment of mitral valve orifice area by Doppler pressure half time in mitral stenosis. Am J Cardiol 1987;60:322-6.

36 Nakatani S, Masuyama T, Kodama K, Kitabatake A, Fujii $K$, Kamada $T$. Value and limitations of Doppler echocardiography in the quantification of stenotic mitral valve area: comparison of the pressure half time and the continuity equation methods. Circulation 1988;77:78-85. 